\title{
FORMAÇÃO DA IDENTIDADE ESPACIAL URBANA NO CONTEXTO DA HIPERMODERNIDADE: UM ESTUDO DE CASO EM REGIÕES ADMINISTRATIVAS DE PELOTAS, RS.
}

\author{
Paula Neumann Novack* \\ *Bacharel e Mestre em Geografia pela Universidade Federal de Pelotas, doutoranda em Geografia pela Pontificia Universidad Católica de \\ Chile. E-mail: paulanovack@gmail.com
}

Recebido em 05/2016. Aceito para publicação em 07/2016.

Versão online publicada em 00/00/0000 (http://seer.ufrgs.br/paraonde)

\begin{abstract}
Resumo: 0 objetivo principal do trabalho consiste em verificar se o contexto da hipermodernidade está relacionado com a formação da identidade espacial, em Pelotas, RS. A pesquisa apresenta uma discussão sobre o conceito de hipermodernidade, bem como identidade espacial urbana que, posteriormente são relacionados com os resultados do trabalho de campo e com o contexto atual da cidade de Pelotas. Do ponto de vista metodológico, foram estudadas duas regiões administrativas de Pelotas: São Gonçalo e Fragata. Também foi realizada uma pesquisa de campo, com entrevistas à população local em uma perspectiva qualitativa. Ainda que não completamente espacializada, os resultados mostram a presença da hipermodernidade no comportamento dos moradores das áreas estudadas em Pelotas.
\end{abstract}

Palavras-chave: Modernização, Hipermodernidade, Identidade, Urbano, Pelotas.

\section{POLÍTICAS PÚBLICAS HABITACIONALES Y LA PRODUCCIÓN DEL ESPACIO URBANO DE RIO GRANDE}

\begin{abstract}
Resumen: El principal objetivo de este trabajo consiste en verificar si el contexto de la hipermodernidad está relacionado con la formación de identidad espacial, en la ciudad de Pelotas, RS. La investigación presenta una discusión sobre el concepto de hipermodernidad, así como el de identidad espacial urbana, los cuales estarán posteriormente relacionados con los resultados del trabajo de campo y con el contexto actual de la ciudad de Pelotas. Desde el punto de vista metodológico, fueron analizadas dos regiones administrativas de la ciudad de Pelotas: São Gonçalo y Fragata. Se llevó a cabo también una investigación de campo, con entrevistas a la población local en una perspectiva cualitativa. Aún que no completamente espacializada, los resultados muestran la presencia de la hipermodernidad en lo comportamiento de los habitantes de las áreas estudiadas en Pelotas. Palabras-clave: Modernización, Hipermodernidad, Identidad, Urbano, Pelotas.
\end{abstract}

\section{HOUSING POLICIES AND THE PRODUCTION OF URBAN SPACE IN THE CITY OF RIO GRANDE}

\begin{abstract}
This work aims in verify whether the context of hypermodernity is related to formation of spatial identity in Pelotas, Brazil. The research presents a discussion about concepts of hypermodernity and urban spatial identity that are later related to fieldwork results and current circumstances of Pelotas. Concerning to methodology, two administrative regions of Pelotas, São Gonçalo and Fragata, were studied. A fieldwork was conducted in order to interview local residents in a qualitative approach. Although not completely spatialized, results point out that hypermodernity presence in residents' behavior in Pelotas studied area.
\end{abstract}

Key-words: Modernization. Hypermodernity, Identity. Urban, Pelotas.

\section{Introdução}

O processo de produção do espaço urbano supera os limites de uma determinação econômica, de trocas e circulação de mercadorias, pois considera os acon- tecimentos sociais, políticos, ideológicos e jurídicos que formam a totalidade de um processo de produção econômico e social. Sendo assim, podemos dizer que o urbano considera para sua totalidade todos os elementos necessários para a produção e reprodução da vida social. Dentre esses elementos destaca as necessidades que cada grupo social tem para sua consolidação, as 
quais estão intimamente relacionadas com os sonhos, desejos de cada um e também com o modo de consumir, pensar, agir sobre uma porção determinada do espaço.

Atualmente a hipermodernidade, a tecnologia e os meios de comunicação estão presentes einfluenciando o comportamento das pessoas com relação à cidade, consequentemente este fenômeno relaciona-se com a formação e transformação da identidade e dos sentimentos e sentidos das pessoas com relação ao bairro ou cidade onde elas vivem. Portanto a sociedade vive em um contexto hipermoderno com influências hipermodernas, mas esse fenômeno nem sempre pode ser identificado espacialmente. A influência da hipermodernidade está posta até mesmo os lugares mais remotos e as populações mais pobres sofrem as consequências desse fenômeno. Cabe aqui ressaltar qual o nível de interferência e qual as dimensões que tal processo traz para o contexto da identidade e da formação dos bairros estudados.

A partir desse contexto de produção do espaço urbano e sua constante transformação é formulada a questão principal da pesquisa que busca verificar a relação da hipermodernidade na construção da identidade no contexto da formação das regiões administrativas Fragata e São Gonçalo, na cidade de Pelotas. Na sequência, o texto apresenta a metodologia utilizada, depois discute os conceitos de hipermodernidade e identidade urbana, por fim apresenta as análises e considerações sobre a pesquisa realizada.

\section{Metodologia}

Para investigar as relações de identidade, fez-se a opção pela entrevista como procedimento metodológico. Para realização dessa verificação, se utiliza as ideias de cotidiano também presente na obra de Lefebvre (1991) considerando as questões relacionadas a família, trabalho e lazer para, a partir disso, identificar qual o grau de envolvimento e até mesmo de isolamento das pessoas em relação a cidade.

A pesquisa faz uma discussão acerca do cotidiano da sociedade relacionada com a hipermodernidade, de acordo com Lipovetsky (2004). Na sequencia realiza-se uma análise dos conceitos de identidade, conforme Carlos (1996). A investigação ressalta que mesmo com a globalização e a tentativa de individualização da sociedade, as identidades culturais locais permanecem, afirmando-se como lugares dotados de identidade e características próprias.

Para escrever sobre a relação dahipermodernidade na construção da identidade e da formação dos bairros, a pesquisa traz uma abordagem qualitativa com proposito de entrevistar os moradores de cada bairro e, a partir disso, analisar sua configuração no que tange aos elementos que demonstram sua identidade e sua formação.

A pesquisa qualitativa é trabalhada no campo da geografia e das demais ciências humanas. Para os geógrafos, a pesquisa qualitativa é fundamental na inserção do pesquisador no contexto de interpretação e interação com objeto de pesquisa e também na adoção de uma postura teórico-metodológica para identificar e analisar fenômenos. Assim como todos os processos existências, a ciência é dinâmica e está em constante processo de transformação, na busca de resultados satisfatórios.

Através dos resultados alcançados os indivíduos são capazes de entender com mais detalhes a realidade onde estão inseridos e assim, podem se posicionar criticamente frente a ela. Assim, o pesquisador propõe análises e discussões para o seu problema de pesquisa e também trabalha que esses resultados alcancem um maior número de pessoas.

Além da pesquisa qualitativa em si, também se utiliza uma abordagem metodológica que está dentro deste contexto, o estudo de caso.

A pesquisa de estudo de caso é uma abordagem qualitativa na qual investigador explora um sistema delimitado contemporâneo da vida real (um caso) ou múltiplos sistemas delimitados (casos) ao longo do tempo, por meio da coleta de dados detalhada em profundidade envolvendo múltiplas fontes de informação (por exemplo, observações, entrevistas, material audiovisual, documentos e relatórios) e relata uma descrição do caso e temas do caso. (CRESWELL 2014, p. 86)

O estudo de caso é uma metodologia muito utilizada pelos cientistas sociais e, como citado acima, possui uma relação íntima com os métodos utilizados na pesquisa qualitativa, por esses motivos é que essa abordagem se encaixa nesta pesquisa. Cabe citar que a pesquisa realiza uma descrição das regiões administrativas estudadas (não uma descrição pura e simples, mas uma descrição crítica do seu atual contexto).

Portanto, a pesquisa busca fazer uma análise qualitativa baseada em entrevistas que possibilitam o entendimento da realidade vivida pelos moradores do bairro Fragata e também do bairro São Gonçalo, ambos com suas peculiaridades e configurações distintas, no que tange a questão temporal. Foram realizadas trinta entrevistas em cada local com perguntas relacionadas ao tempo em que a pessoa mora no bairro, se a mesma conhece o histórico de formação do bairro e também questões relacionadas aos aspectos cotidianos da vida urbana. Entre os elementos que compõem a vida nas cidades foram aplicadas questões que envolvem principalmente as relações entre trabalho, família e lazer que 
estão fundamentalmente presentes na vida das pessoas que habitam e produzem a sociedade urbana.

As questões sobre o cotidiano investigaram os locais onde as pessoas consomem, onde elas estudam ou trabalham, onde fazem suas refeições. Perguntou-se também que espaços o entrevistado utiliza para lazer, se tem parentes ou amigos em outro bairro da cidade e se costuma visitá-los. Ainda questionamos se o morador deixa de ir a algum lugar da cidade que gostaria de frequentar, em caso de resposta afirmativa, se questiona o motivo que impede. Além disso, também se perguntou quanto tempo diário cada entrevistado passa na internet. Essas questões foram realizadas para fazer uma análise do grau de isolamento e individualização que cada morador possui em relação ao bairro e a cidade onde vive.

Para além das metodologias anteriormente citadas, também foi realizada uma pesquisa que envolve uma ampla revisão bibliográfica sobre a temática do trabalho que, possibilitou a seleção de textos que contribuem para o estudo de caso das regiões administrativas Fragata e São Gonçalo.

\section{A Hipermodernidade}

A hipermodernidade caracteriza a sociedade atual. É possível dizer que a sociedade hipermoderna sofre grande influência da globalização e também dos processos de individualização dos lugares. A sociedade sofre influência de muitas informações que possibilitam e facilitam o processo de individualização. Esse processo fica evidente através dos referenciais que estudam a sociedade hipermoderna e também quando se analisa a conjuntura atual do corpo social através da observação e a própria vivência do cotidiano.

Mesmo com a tentativa de homogeneizar os lugares, as experiências e as peculiaridades do local possibilitam um processo de resistência que torna esse procedimento falho no sentido que, "A homogeneização dos gostos e dos modos de vida não desemboca numa vida política e social consensual: perduram os conflitos, mas por meio de uma pacificação individualista do debate coletivo, para qual a mídia contribui." (LIPOVETSKY, 2004 p. 43)

Portanto, pode-se dizer que a hipermodernidade não configura uma sociedade perfeita e feliz onde existe uma verdade absoluta. Ao passo que a tentativa de homogeneização dos lugares tende a desconstruir algumas características locais, também configura a vantagem do acesso às informações e possibilidade de realizar adaptações por influência da globalização, para melhorar e facilitar as atividades da vida cotidiana.

0 que existe dentro desse contexto é uma possível desvalorização das tradições e das culturas locais. Além disso, uma despreocupação com os bem públicos e em consequência disso uma valorização do consumo de produtos universalizados e também de serviços ligados ao setor privado. Todo esse processo que envolve a hipermodernidade, a valorização do consumo e do privado, tem grande influência da mídia e dos meios de comunicação. Estes vendem uma imagem de felicidade que é configurada através do consumo de produtos instantâneos que trazem satisfação e alegria imediata para a vida cotidiana.

A hipermodernidade valoriza o modo capitalista de produção, a falsa ilusão da felicidade e bem-estar comprados é um dos problemas potencializados por essa realidade. A valorização do poder de compra e de consumo é um dos fatores que faz aumentar o individualismo e também influi na variação do comportamento humano. Assim pode-se dizer que:

O hiperindividualismo coincidi não apenas com a internalização do modelo homo oeconomicus que persegue a maximização de seus ganhos na maioria das esferas da vida (escola, sexualidade, procriação, religião, política, sindicalismo), mas também com a desestruturação de antigas formas de regulação social dos comportamentos, junto a uma maré montante de patologia, distúrbios e excessos comportamentais. Por meio de suas operações de normatização técnica e de desligamento social, a era hipermoderna produz não só movimento a ordem e a desordem, a independência e a dependência subjetiva, a moderação e a imoderação. (LIPOVETSKY, 2004 p. 56)

Portanto a hipermodernidade, ao mesmo tempo em que proporciona e potencializa o individualismo, também faz com que as pessoas queiram manter vínculos sociais e busquem novas formas de relacionamentos, sejam eles amorosos, de amizade ou até mesmo familiares. Com o passar do tempo, alguns comportamentos mudaram, as pessoas se sentem mais livres para dizerem o que pensam e também para fazerem o que desejam. Deste modo, novas formas de relacionamento, de interação com o mundo e com os lugares surgem, estes fatores também influenciam na formação da identidade e no relacionamento com as tradições e costumes de cada local.

As relações são muito intensas e rápidas no âmbito da hipermodernidade, tudo é instantâneo, as pessoas vivem cada vez mais em função do relógio, passam a maior parte do tempo realizando atividades simultâneas, em ritmo frenético. A sociedade hipermoderna pode ser considerada uma sociedade escrava do tempo, do produtivismo. "A sociedade hipermoderna se apresenta como uma sociedade em que o tempo é cada vez mais vivido como preocupação maior; a sociedade em que se exerce e se generaliza uma pressão temporal 
crescente". (LIPOVETSKY, 2004 p. 75)

Desse modo, é importante ressaltar que a hipermodernidade segue aliada ao processo de produção capitalista atual. Portanto, todos os seres humanos são sujeitos ativos nesse processo de produção chamado de hipermoderno. Mas ao mesmo tempo em que todos, de alguma forma, participam desse processo também manifestam algumas resistências a tal produção.

Por mais que existam grupos com umaidentidade característica, também existe um movimento de individualização e de aceitação aos meios de comunicação que facilitam e proporcionam que as pessoas sejam cada vez mais independentes, criando relações digitais que, por vezes, afastam do convívio social e do coletivo. Este é um fator que também afasta as vivências tradicionais e também os saberes locais.

Muitas são as contradições que acompanham a hipermodernidade a influência da mídia, o incentivo a individualização e também a independência causam, em muitos casos, abalos na vida social e na produção da vida cotidiana. A sociedade está cada vez mais independente e fechada em seus mundos particulares e ao mesmo tempo com acesso a todas as informações e acontecimentos globais que podem ser acompanhados pela internet.

Assim se configura um processo de afastamento do local e uma aproximação do global, totalmente influenciada pelas novas formas de relacionamento e trabalho pelos meios de comunicação ligados a internet. Dentro de toda essa análise, considerando o processo de individualização, se pode dizer que a hipermodernidade tem como força motriz o tempo. Este é indissociável a tal processo e realmente dita as regras e o ritmo em que as relações sociais e de produção acontecem no espaço.

Ainda sobre a influência da hipermodernidade no processo de produção da sociedade, cabe enfatizar que tal processo demonstra e incentiva a queda e o enfraquecimento dos movimentos que apoiam e incentivam a defesa de ideais coletivos, de grupos sociais, das vivências e relações familiares. As ações hipermodernas estão sempre relacionadas com o individual, incentivando e potencializando uma vida independente onde a produção da vida e do consumo de produtos são sempre individuais.

A cultura hipermoderna se caracteriza pelo enfraquecimento do poder regulador das instituições coletivas e pela automização correlativa dos atores sociais em face das imposições do grupo, sejam da família, sejam da religião, sejam dos partidos políticos, sejam das culturas de classe. Assim, o individuo se mostra cada vez mais aberto e cambiante, fluido e socialmente independente. Mas essa volatilidade significa muito mais a desestabilização do eu do que a afirmação triunfante de um individuo que é senhor de si mesmo. (LIPOVETSKY, 2004 p. 83)

Até mesmo o valor de uso e de troca assumem outras dimensões, a mídia incentiva e coloca um valor emocional nos produtos. As propagandas, cada vez mais, incentivam o consumo dos produtos como se fosse impossível viver sem tal. Além disso, também colocam um juízo de valor sobre os mesmos, dizendo que só são felizes e completos os indivíduos que podem adquirir determinado bem material. Nessa lógica, pessoas que consomem mais podem encontrar a satisfação pessoal que as pessoas que não consomem ou que não podem consumir. Estas pessoas são vistas como incompletas e na maioria das vezes ficam a margem da sociedade.

Por fim, a sociedade hipermoderna como já citado, tem um papel que configura uma sociedade cada vez mais independente e individual. Dentro dessa perspectiva, atuam os meios de comunicação e informação, sempre incentivando as pessoas a independência e ao consumo de bens materiais individuais. Mas ao mesmo tempo existe um movimento em direção à busca das vivências sociais que hoje, são realizadas através da internet.

A mesma sociedade hipermoderna que afasta e segrega também une e agrega. É um processo contraditório e dinâmico que conduz uma sociedade que vive em função do tempo, com forte influência da mídia e dos acontecimentos e modismos globais, mas que ao mesmo tempo valoriza a cultura e as peculiaridades que se manifestam em pequena escala, a escala do local, onde se configuram as identidades.

A sociedade atual pode ser chamada de hipermoderna porque está relacionada com a mídia, com a internet entre outros. Mas ao mesmo tempo também está relacionada com a vida cotidiana, com os acontecimentos diários que dão ritmo à vida. 0 sujeito é um ser social que está intimamente ligado à construção vida e em todos os processos de transformação que ocorrem, tem sua participação.

\section{A Identidade Urbana}

A discussão de identidade está vinculada à formação dos bairros, com a importância do local e também com as ações dos moradores que vivem e produzem o bairro. A identidade tem uma relação muito próxima com o conceito de lugar e este acentua as relações entre as pessoas com o plano do vivido, do imediato e assim constrói uma identidade local concreta.

Sendo assim é possível afirmar que:

A natureza social da identidade, do senti- 
mento de pertencer ao lugar os as formas de apropriação de espaço que ela suscita, liga-se aos lugares habitados, marcados pela presença, criados pela história fragmentaria feita de resíduos de detritos, pela acumulação dos tempos, marcados, remarcados, nomeados natureza transformada a prática social, produto de uma capacidade criadora, acumulação cultural que se inscreve num espaço e tempo. (CARLOS, 1996, p. 30)

"Todavia deve-se também considerar que ela também contempla, na multiplicidade das práticas sociais que produz identidades entre áreas no seu interior criando lugares distintos a partir de usos diferenciados". (CARLOS, 1996, p. 69)

Outro fator que influência diretamente na formação da identidade dos indivíduos e dos grupos sociais está relacionado à memória. "A memória articula espaço e tempo com base em uma experiência vivida de determinado lugar. Nesse sentido a construção do lugar se revela, fundamentalmente, como construção de uma identidade" (CARLOS 2001, p. 217)

Sendo assim, cabe destacar que a memória sempre associa tempos e espaços, revela necessidades e desejos que configuram os elementos de construção da identidade entre o indivíduo e o espaço. A relação casa-bairro se liga à presença, por isso é parte integrante da identidade.

A casa é o principal elemento de identificação com o lugar e também da realização da vida, este fator marca um uso privado, é o elemento do conforto e da segurança do corpo. Portanto, o habitar envolve outras dimensões é assim que, a partir da casa, se constroem elementos que compõem os indícios que geram uma base segura para a construção da identidade. Essa construção acontece a partir da casa, mas estendida ao bairro e à cidade. Aqui gestam as relações com o outro, para além daquela dos membros da família.

0 sentido que os habitantes dão ao bairro emerge de suas vidas, é no uso que a identidade se cria, com as referências que delimitam as ações cotidianas, possibilitando o sentido de descoberta. Mas além da identidade formada espontaneamente pela vivência e apropriação do espaço, existe também uma identidade criada. Esta muitas vezes é desenvolvida pelo poder público, por uma equipe de técnicos, que buscam organizar e classificar a cidade.

As mudanças na vida cotidiana aparecem como perdas de certo estilo que a vida tinha e não tem mais; como decorrência de sua normatização e da constituição de uma identidade que passa agora por valores, constituídos pelo mundo da mercadoria, criador da identidade abstrata (movimento que se refere à passagem do individuo do "ser alguém" para o "ter algum objeto"). E aqui a mercadoria é principalmente a casa. (CARLOS 2001, p. 249)

O lugar de um bairro é construído por um grupo de pessoas que vive em uma determinada porção do espaço porque se engajaram em um movimento de identidade comum e um objetivo comum. Esse lugar criado dentro de grupo social tem uma identidade com caráter político, social e cultural, e, além disso, redimensiona a infraestrutura e as novas relações sociais, econômicas e culturais.

Essa construção estabelece a multiplicidade do espaço vivido. Pouco a pouco esse lugar vai produzindo seus próprios símbolos e identidades, esse conjunto de significados e estratégias vão se multiplicar em um conjunto de ações. Essas ações fazem referência à identidade cultural formada entre as pessoas com o espaço. Cabe ressaltar que as mudanças realizadas na dimensão local causam transformações no bairro, essas transformações são construídas a partir da apropriação e da produção do espaço. Essa apropriação só é possível através da construção da identidade.

\section{As Regiões Administrativas De Pelotas: Os Bair- ros}

As Regiões Administrativas foram criadas durante os estudos para a elaboração do III Plano Diretor de Pelotas. A cidade foi dividida em três níveis de planejamento, representado por distintas escalas definidas como Macrorregiões, Mesorregiões e Microrregiões. As Macrorregiões Administrativas correspondem às divisões tradicionalmente reconhecidas como dos grandes bairros da cidade, o Centro, o Fragata, a Barragem, as Três Vendas, o Areal, o São Gonçalo e o Laranjal.

No interior de cada Macrorregião foram identificadas áreas entendidas como Mesorregiões Administrativas. Para efeitos de planejamento, correspondem às parcelas das Macrorregiões, com identidade própria, muitas vezes identificadas pela sociedade como verdadeiros bairros, mas que, por estarem no interior de unidades principais foram considerados como Mesorregiões. 


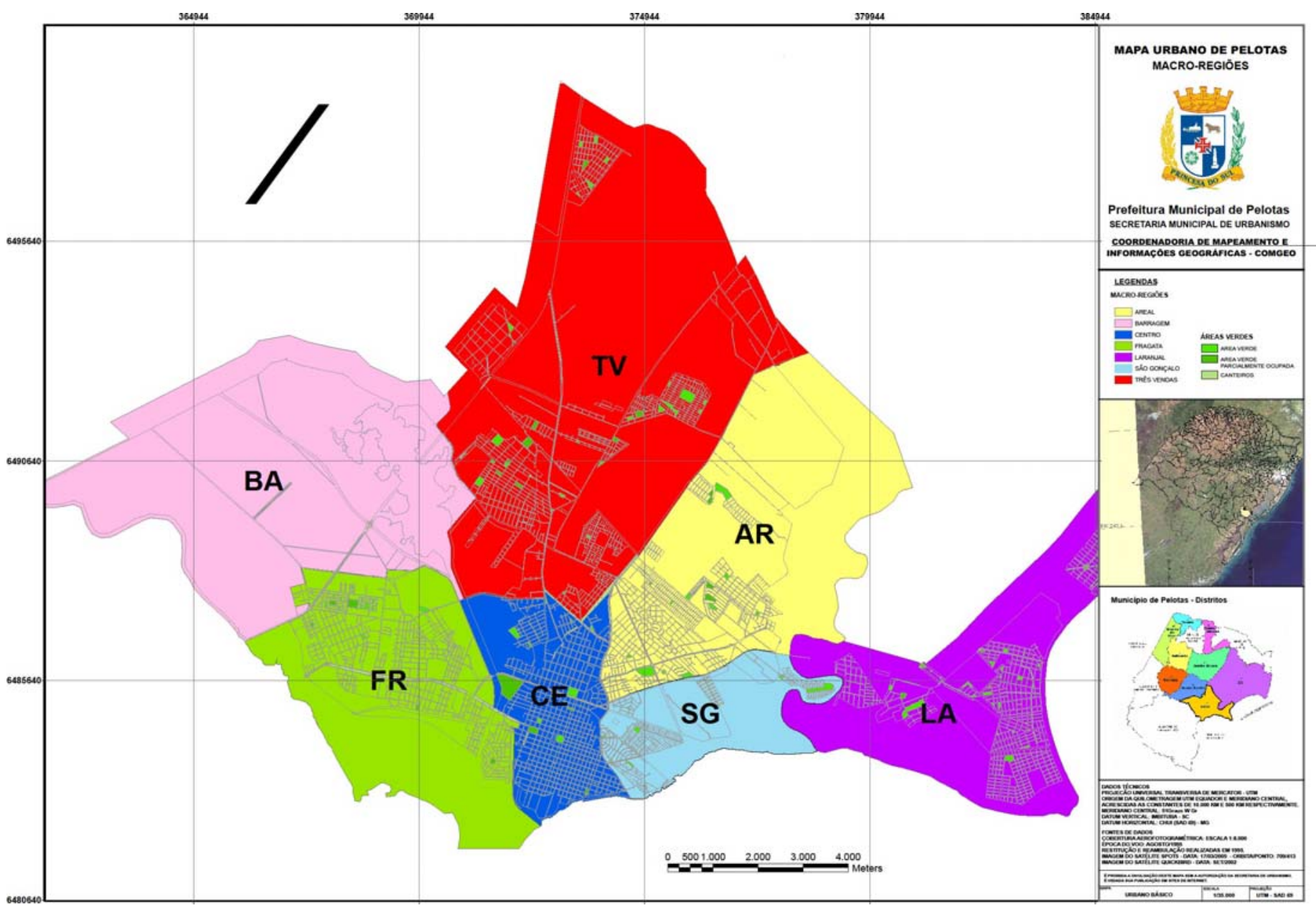

Fonte: http://www.pelotas.com.br/. Data: acessado em 2014.

\subsection{Região administrativa São Gonçalo}

Em pesquisas anteriores foram levantados alguns dados sobre a região administrativa São Gonçalo que possibilitaram este estudo relacionado à hipermodernidade e sua relação com a identidade na região administrativa citada e também na região administrativa do

Fragata na cidade de Pelotas. Sobre a região administrativa São Gonçalo é possível dizer que a mesma foi criada, através da Lei № 5.490, de 24 de Julho de 2008.

A novidade da Lei está relacionada justamente da criação da região administrativa São Gonçalo, que não existia. Ela foi identificada no processo de planejamento que levou ao terceiro plano diretor. Na época, foi possível perceber que os moradores daquele local não se identificavam nem com a região administrativa do centro, nem com a região administrativa Areal, aos quais faziam parte.

Além disso, o plano diretor tinha como uma das diretrizes do planejamento, a valorização do Canal São
Gonçalo, por ser uma área de potencial paisagístico e de lazer que, no entanto, estava escondida. 0 nome do novo bairro, além de proporcionar uma nova identidade, também ressalta o próprio Canal. Esta área hoje tem sido cobiçada pelos investidores. A construção de condomínios fechados são exemplos significativos.

O bairro São Gonçalo é demarcado a leste peloArroio Pelotas, oeste pelo canal do pepino na Rua Juscelino Kubitschek, sul pelo canal São Gonçalo e a norte pela Avenida Ferreira Viana. Suas principais vias de desenvolvimento além dos seus limites originais são a Rua São Francisco de Paula e Avenida Ferreira Vianna. A área era pouco urbanizada, mas se tornou uma opção de expansão urbana por conta de seus vazios.

Atualmente o bairro possui uma população de 28.582 habitantes de acordo com os dados do último censo realizado pelo IBGE, no ano de 2010. Ainda sobre as informações levantadas pelo IBGE, cabe destacar que $67,9 \%$ da população é branca, 18,7\%, negra, 0,4\%, amarela e $13 \%$, parda. 


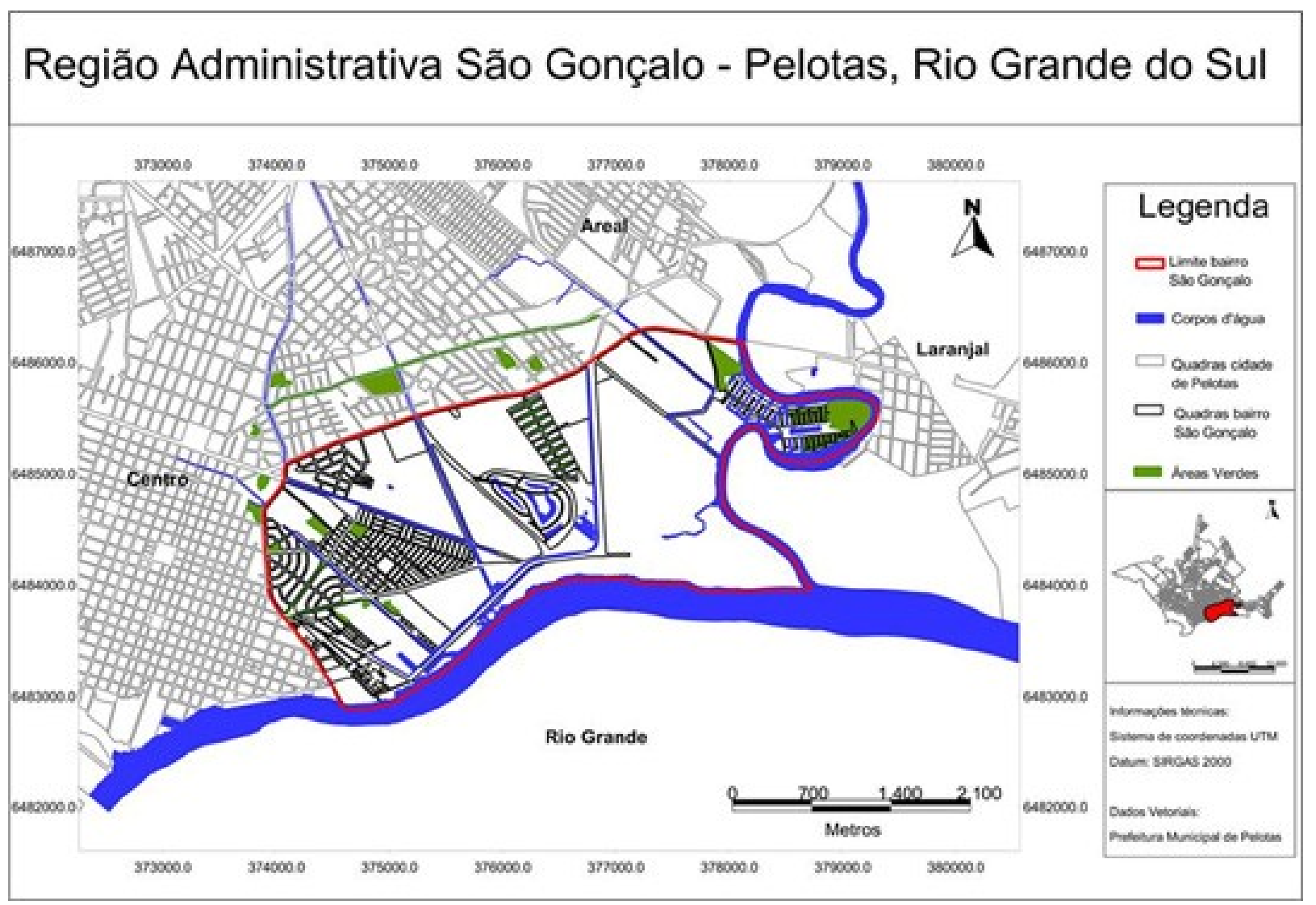

Fonte: ARNDT, Artur Lacerda. Data: Agosto de 2014.

\subsection{Região administrativa Fragata}

A região administrativa Fragata possui um histórico de formação e uma configuração diferente daregião administrativa São Gonçalo, apresentada anteriormente. Essa região administrativa tem uma importância significativa junto à formação e extensão da cidade de Pelotas.

O Fragata está localizado na zona oeste da cidade de Pelotas, possui uma grande área de aproximadamente $47.420 .688,50 \mathrm{~m}^{2}$. Suas principais ruas e avenidas de acesso são a Avenida Duque de Caxias, Avenida Lisboa, Avenida Assis Brasil e Avenida Pinheiro Machado. 0 mesmo tem uma formação que possibilita o acesso a vários outros bairros da cidade e também para as rodovias BR-392 que também se relaciona com a BR116 umas das principais rodovias do país.
Esta região administrativa também chamada de bairro cidade, tem uma população de 75.238 habitantes. 0 bairro não é chamado de bairro-cidade por conta de sua densidade populacional, mas sim por conta de sua configuração que abriga diversas funções urbanas, dentre as quais podemos destacar a importância do comércio que se concentra principalmente na Avenida Duque de Caxias.

No decorrer desta Avenida é possível identificar a presença do comércio em suas diversas formas; o comércio alimentício tem uma forte influência na configuração e na concentração de pessoas que possibilitam o movimento e o encontro nesse local. Ainda concentra supermercados e mercados menores que vendem produtos alimentícios industrializados. Possui também um centro comercial chamado Bairro Cidade, além de floriculturas, lojas de eletrodomésticos, vestuário, artesanato, entre outros. 


\section{Região administrativa Fragata - Pelotas, Rio Grande do Sul}

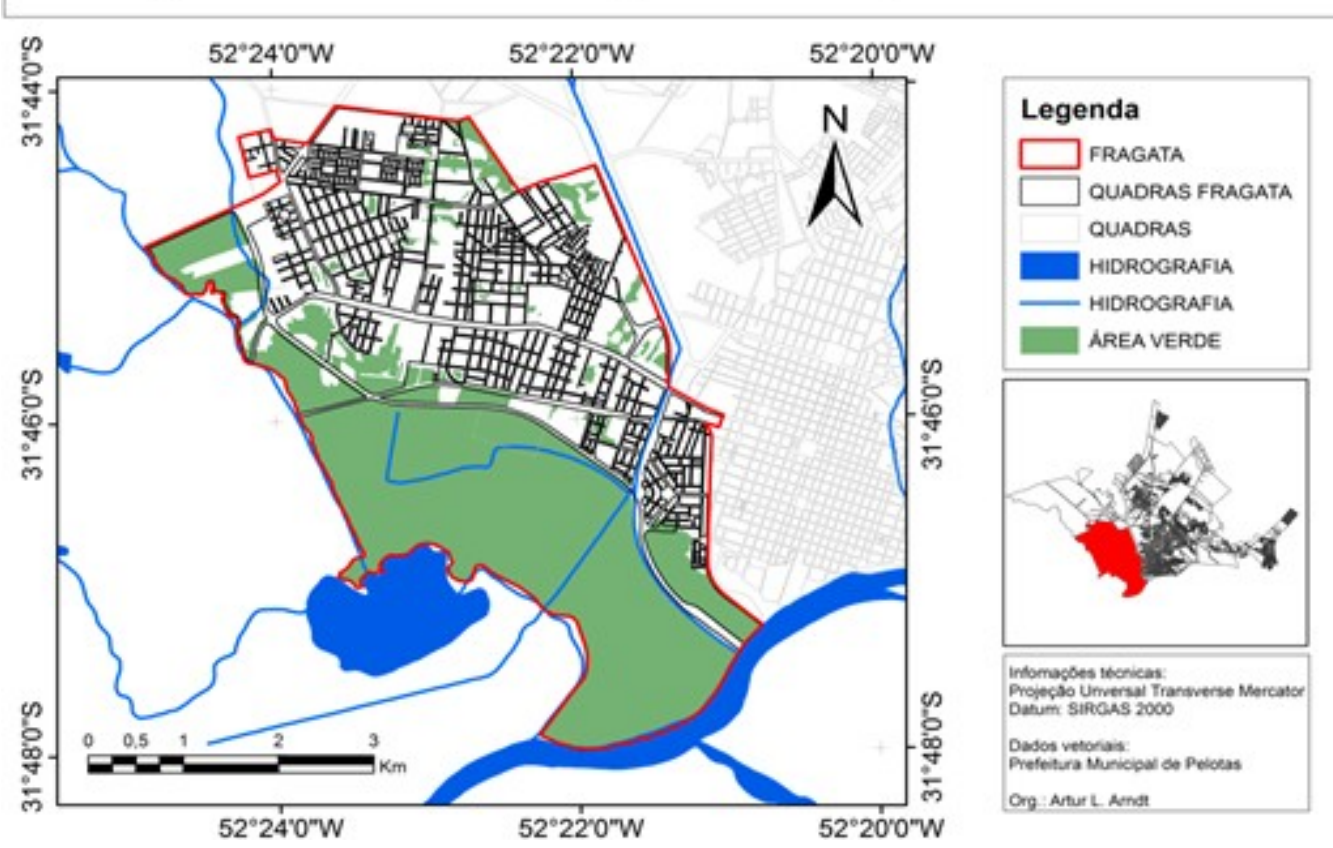

Fonte: ARNDT, Artur. Data: Junho de 2015

\subsection{Estudo Comparativo entre as Regiões Adminis- trativas pesquisadas}

Neste momento realiza-se uma análise dos resultados obtidos através da pesquisa de campo. A partir dos questionamentos, são respondidos os objetivos do trabalho e analisa-se como a vida cotidiana se efetiva nesses dois bairros de Pelotas. Depois de analisar as respostas dos moradores, se apresenta uma discussão sobre a relação da hipermodernidade com a identidade que encontrada nas falas dos moradores das regiões administrativas pesquisadas.

Primeiramente, foram analisadas as entrevistas realizadas com os moradores da região administrativa São Gonçalo, posteriormente as respostas dos moradores da região administrativa do Fragata. Por fim discute-se os resultados encontrados nas duas regiões administrativas para responder o principal objetivo do trabalho.

Sobre as origens do bairro, somente dez por cento dos entrevistados disse conhecer ou já ter ouvido falar sobre o histórico do local e essa porcentagem representa três moradores dos trinta entrevistados na área do bairro. A maioria dos moradores disse não conhecer efetivamente os motivos que levaram o local a ser ocupado.

Com relação aos lugares onde consomem e compram os produtos de necessidade cotidiana, quatro moradores responderam que consomem dentro da região administrativa, dezenove moradores disseram consumir fora da área do bairro. Foram contabilizadas também sete pessoas, que responderam que consomem dentro e fora do bairro.

Entre os trinta entrevistados, cinco moradores disseram trabalhar dentro da região administrativa São Gonçalo, vinte e um responderam que trabalham ou estudam fora do local e quatro pessoas disseram que atualmente não estudam e nem trabalham fora de casa. Pode-se identificar que a maioria dos moradores entrevistados exercem suas atividades profissionais fora da área que pertence à região administrativa.

Quando questionados sobre deixar de frequentar algum lugar da cidade que gostariam e por qual motivo isso acontece, sete pessoas responderam que sim e vinte e três pessoas responderam que não, os motivos foram variados. Algumas pessoas responderam que deixam de frequentar lugares da cidade por falta de estrutura, como praças. Citaram também a violência que vem crescendo em alguns locais da cidade, falaram que alguns lugares são distantes e que o transporte é precário. Os moradores que disseram que não deixam de ir a lugares da cidade que gostam de frequentar, também citaram alguns problemas encontrados na área urbana de Pelotas, enfatizaram principalmente a falta de policiamento e segurança na cidade.

Sobre uso da internet, cinco entrevistados responderam que passam até duas horas diárias conectados à internet, nove pessoas afirmaram que ficam de duas a três horas conectadas por dia, treze moradores disseram que ficam mais de três horas por dia navegando e utilizando a internet e três pessoas disseram não utili- 
zar a internet com um meio de comunicação e distração.

As vinte e sete pessoas que utilizam a internet disseram que utilizam essa ferramenta como um meio de comunicação e de relação com os amigos, com os parentes e com o mundo de uma forma mais geral, afirmaram que utilizam cada vez menos as ligações por telefone ou celular. Disseram também, que não precisam estar fisicamente próximas das pessoas para estarem perto delas e, além disso, utilizam a internet como um meio de diversão onde podem acessar o que desejam, em qualquer momento do dia.

Este fator enfatiza a presença e a influência da hipermodernidade na vida das pessoas, mesmo que elas não percebam, buscam ao mesmo tempo sua individualidade, mas também sua inserção na sociedade. Dessa forma, mesmo que a hipermodernidade não se especialize e forma efetiva dentro do bairro com um alto grau de isolamento. A mesma está presente e pode ser observada através dos comportamentos humanos de uma sociedade cada vez mais individualizada, mas que a todo instante busca estar conectada ao mundo.

Depois de discorrer sobre os resultados dos questionamentos realizados na região administrativa São Gonçalo, são analisados os resultados encontrados para a região administrativa do Fragata. Os questionamentos realizados foram os mesmos do São Gonçalo seguindo a discussão dos resultados encontrados.

Quando questionados sobre o conhecimento sobre o histórico de formação dos bairros, uma partesignificativa dos trinta entrevistados disse conhecer pelo menos parte do histórico de formação do bairro Fragata. Assim quatorze dos moradores disseram conhecer o histórico do bairro Fragata e dezesseis pessoas disseram não saber muito sobre a formação do local.

Sobre o questionamento que envolve os locais onde os moradores consomem e compram os produtos que consideram importantes para a seu cotidiano, os mesmos ficaram bastante divididos, na medida em que dez entrevistados disseram consumir dentro da área ocupada pelo bairro, sete moradores destacaram que consomem fora do bairro e treze pessoas enfatizaram que compram dentro e fora da área ocupada pelo Fragata.

Com relação às atividades exercidas pelos entrevistados, oito trabalham dentro do bairro, dezenove pessoas disseram estudar ou trabalhar fora do local e três pessoas não exercem nenhuma dessas atividades no momento. Assim como no bairro São Gonçalo, a maioria dos entrevistados não trabalham ou estudam fora da região administrativa em questão.

Quando os moradores foram questionados se deixam de ir a algum local da cidade que gostariam de frequentar pode-se observar que a maioria responde que não. Mas a porcentagem de pessoas que deixam de ir aos lugares que gostaria de ir também é expressiva. Nesse caso, dezenove pessoas responderam que não deixam de frequentar os lugares e onze pessoas res- ponderam que sim.

Sobre os motivos que as fazem deixar de frequentar algum local da cidade, as pessoas destacaram principalmente a questão da violência, como foi também citado pelos moradores do bairro São Gonçalo. Porém, os moradores do Fragata foram ainda mais enfáticos nessa questão e mencionaram lugares específicos da cidade onde julgam que esse fenômeno ocorre com mais intensidade e frequência, citaram os bares do Porto e também o centro da cidade.

0 último questionamento das entrevistas perguntava aos moradores quanto tempo por dia eles ficam conectados à internet como um elemento de distração e conexão com outras pessoas. Nas respostas seis pessoas disseram que ficam conectadas de uma duashoras por dia, cinco pessoas disseram que ficam na internet de duas a três horas diárias, quinze pessoas responderam que ficam mais de três horas por dia acessando a internet seja no computador ou em outros aparelhos e quatro pessoas disseram que não acessam a internet.

Assim como no bairro São Gonçalo a questão da individualização e do isolamento total não acontece de forma expressiva no espaço. Mas é possível notar a influência de aparelhos ligados a hipermodernidade na vida das pessoas. A hipermodernidade está presente no ambiente e nas relações que se efetivam dentro da cidade, elas podem não ser visivelmente materializadas, mas estão presentes nas ações e nos comportamentos das pessoas que são socialmente construídas e que são também resultado do modo de produção em que vivem.

\section{Considerações Finais: Pelotas e a Permanência da Modernidade}

Neste momento discute-se efetivamente os resultados da pesquisa relacionados aos objetivos e ao estudo de caso realizado. A problemática da pesquisa se preocupada em analisar a existência da relação entre a hipermodernidade na construção da identidade, considerando as regiões administrativas Fragata e São Gonçalo na cidade de Pelotas. Por isso, nas entrevistas foram investigadas questões relacionadas aos hábitos cotidianos das pessoas, para avaliar qual o envolvimento e identidade que elas possuem com relação ao local. Além disso, com as entrevistas também foi possível identificar a influência da hipermodernidade no cotidiano dessas pessoas.

Com as perguntas anteriormente citadas, pode-se verificar que as pessoas possuem um envolvimento significativo com os bairros pesquisados principalmente no Fragata, onde os moradores disseram encontrar os produtos que necessitam para a vida cotidiana. Mas ao mesmo tempo, a maioria disse ter uma relação frequente com o centro e também com outras áreas da cidade, o que configura uma permeabilidade entre os bairros e 
o centro de Pelotas.

Através da análise das questões da pesquisa, podemos observar que a maioria dos moradores circula pela cidade ou pelo menos em parte dela. Esse fator nos possibilita afirmar que a cidade tem uma configuração espacial relacionada com a modernidade e pós-modernidade do que propriamente com a hipermodernidade. As identidades presentes não são totalmente individualizadas e isoladas onde os bairros não se comunicam, mas são identidades que reconhecem a importância do centro e de outros bairros.

Uma questão presente nas entrevistas realizadas com os moradores perguntava sobre os locais que eles utilizavam para lazer e em praticamente todos os casos, os moradores citaram locais dentro e fora das regiões administrativas a que pertencem. Este é outro fato que demonstra a permeabilidade e a mobilidade que as pessoas exercem pela cidade, os principais locais citados foram o Laranjal, o Parque da Baronesa, os Bares do Porto, o Quadrado, o Shopping Pelotas e também o centro da cidade.

Com base na pesquisa de campo, é possível dizer que esse processo de total isolamento não ocorre em Pelotas. A cidade possui características de uma cidade de porte médio, onde os lugares se comunicam e criam uma dinâmica fragmentada que tem suas bases na modernidade e não na hipermodernidade.

Com relação à identidade das regiões administrativas pesquisadas, observa-se que os moradores da região administrativa do Fragata têm uma relação mais intensa com o local do que os moradores entrevistados na região administrativa São Gonçalo. Quando questionados sobre a formação do local, os moradores do Fragata demonstraram conhecer um pouco mais das origens do bairro. Os moradores do bairro São Gonçalo não souberam falar exatamente sobre a formação do bairro, não deram respostas afirmativas e a maioria respondeu que não conhecia as origens do bairro.

Ainda no caso específico do Fragata, os moradores demonstram interesse em falar um pouco mais sobre as características do bairro e também da afinidade que possuem com o local. No São Gonçalo, mesmo as pessoas que moram a mais de vinte anos no local, falaram pouco sobre as características do bairro, e não foram enfáticos em exaltar fatores positivos do bairro.

Seguindo na análise entre os dois bairros, pode-se dizer que no que diz respeito ao consumo, a maioria dos moradores do São Gonçalo enfatizaram que compram a maior parte dos produtos que utilizam fora da área ocupada pelo bairro. Por outro lado, no caso do Fragata, os moradores enfatizaram que consomem dentro e fora do bairro, mas que o local possui os produtos que eles necessitam para viver. Os moradores do Fragata ressaltaram também que só consomem no centro e em outros locais por conta da variedade e diferença de preços entre os produtos.

Esta posição dos moradores é mais um elemento que justifica e demonstra a relação de identidade com o local, essas relações também podem ser mais intensas por conta da consolidação do bairro dentro da cidade de Pelotas. Como citado, o bairro é um dos lugares mais antigos da cidade de Pelotas e também por isso possui uma consolidação e um reconhecimento tanto para os moradores, como para moradores de outros lugares da cidade.

No entanto, esse processo não ocorre com tanta intensidade na região administrativa do São Gonçalo, porque este lugar tem uma formação mais recente e que não foi amplamente consolidada. Este lugar ainda está passando por um processo de ocupação e de criação e formação de identidades.

O São Gonçalo tem uma configuração diferente do Fragata, esse bairro está sofrendo influências de características hipermodernas no seu processo de ocupação e consolidação. 0 caso do Fragata é um pouco diferente, porque ele sofre influências da hipermodernidade, mas sua configuração espacial está consolidada. O São

Gonçalo possui em sua área empreendimentos com características hipermodernas e o Fragata é um bairro mais tradicional, com residências e comércios ligados as características da modernidade e pós-modernidade.

Ainda sobre os resultados das entrevistas, é possível dizer que os moradores do Fragata e do São Gonçalo, em sua maioria, trabalham ou estudam fora destes lugares. As respostas dos moradores abrangem diversos locais dentro da cidade de Pelotas e até mesmo fora dela. Esta é outra característica que exemplifica a dependência e a ligação que os bairros possuem entre si, mas principalmente em relação ao centro da cidade que concentra as atividades empregatícias e também de formação acadêmica.

Sendo assim, é possível destacar que mesmo as atividades cotidianas realizadas nos bairros não estão relacionadas efetivamente com o processo de individualização e isolamento das pessoas. Mas sim, com questões relacionadas com a limitação financeira existente entre os moradores entrevistados.

Outro fator que comprova que as características e influências hipermodernas ainda não se efetivaram espacialmente na cidade, está relacionada à questão que indagava se o morador deixava de frequentar algum lugar da cidade que gostaria. Nesse sentido, a maioria das repostas foram negativas, ou seja, a maioria das pessoas não deixa de frequentar outros locais da cidade por motivos individualistas. Assim fica comprovado mais um elemento relacionado à cidade fragmentada e não totalmente influenciada pela hipermodernidade.

Com relação ao uso da internet, a grande maioria dos entrevistados utiliza o recurso não só para trabalho, mas também para entretenimento e relacionamentos sociais. Parte dos entrevistados disseficar diariamente mais de três horas conectados, esse é um elemento que comprova a presença da hipermodernidade na vida das pessoas.

Retomando a questão principal da pesquisa que tem como objetivo verificar em que medida esse pro- 
cesso da hipermodernidade está relacionado com a formação da identidade em casos concretos, pode-se dizer que a questão da hipermodernidade influência no cotidiano das pessoas, mas ela não apareceespacializada.

Observa-se que existem elementos constitutivos da sociedade que apontam para essa hipermodernidade e que também apontam para uma autonomização. Mas a cidade ainda é muito conectada entre si e, portanto, não há essa separação, isso caracteriza uma espacialidade moderna, pós-moderna e não hipermoderna.

Ainda dentro dos resultados dessa análise final, é possível afirmar a que os habitantes da cidade dePelotas apresentam em seu comportamento algumas influências da hipermodernidade, como o isolamento e ao mesmo tempo a inserção dos indivíduos na sociedade através do uso da internet e das redes sociais. Este é um processo cada dia mais intenso e presente na vida das pessoas, independente de idade, classe e outros elementos que compõem a vida social.

Sobre as influências espaciais, destaca-se a chegada e o processo de implantação de condomínios fechados que possuem uma configuração independente den-

tro das suas dependências. Esses empreendimentos estão em processo de implantação na cidade de Pelotas, o que comprova que as influências hipermodernas tendem a se espacializar na cidade nos próximos anos.

Para finalizar, é importante enfatizar que as influências da hipermodernidade estão presentes nas regiões administrativas pesquisadas e consequentemente em toda a cidade de Pelotas. Cabe ressaltar que a hipermodernidade está presente no comportamento da sociedade atual e que no caso de Pelotas ela ainda não está totalmente presente no espaço, mas com o tempo esse processo pode se efetivar.

\section{Referências}

CARLOS, Ana Fani Alessandri. o lugar no/do mundo. São Paulo: Hucitec, 1996.

CARLOS, Ana Fani Alessandri. Espaço-tempo na metrópole: a fragmentação da vida cotidiana. São Paulo: Contexto, 2001.

CRESWELL, John. Investigação Qualitativa e Projeto de Pesquisa. Porto Alegre: Penso Editora, 2014.

LIPOVETSKY, Gilles. Os Tempos Hipermodernos. São Paulo: Barcarolla, 2004.

PREFEITURA MUNICIPAL E PELOTAS. III Plano Diretor de Pelotas. Pelotas: PMP, 2008.

SOARES, Paulo Roberto Rodrigues. Del proyecto urbano a la producción del espacio: morfología urbana de la ciudad de Pelotas, Brasil (1812-2000). Barcelona, 2002. Diss. Tese (Doutorado). Universidade de Barcelona.

VIEIRA, Sidney Gonçalves. A Cidade Fragmentada: o Planejamento e a Segregação Social do Espaço Urbano em Pelotas. Pelotas: Ed. UFPel, 2005. 